\title{
NSF Workshop: Supporting Materials Research
}

Recently the National Science Foundation (NSF) convened a panel of materials representatives from universities, industries, and national laboratories to hold a one-day Workshop on the NSF Advanced Materials and Processing Program (AMPP). A summary of the preliminary Workshop report is given in the Washington News department in this issue of MRS Bulletin. Having been one of the panelists, I here discuss the context for the Workshop. It tells much about the critical need for our community to represent materials research to a broader audience, especially in the current climate of severe budgetary belt-tightening. If the materials community fails to argue effectively for its utility to society, we cannot expect anyone to come to our rescue.

The AMPP is one of seven cross-cutting strategic areas ${ }^{1}$ used by NSF to describe over half of its budget, the balance of funding being distributed to nondesignated areas. The AMPP area currently represents slightly over $\$ 200$ million in funding, corresponding to approximately 2,000 awards, and covers a wide spectrum of research and education activities ranging from condensed matter and materials physics and materials chemistry and chemical processing to materials science and engineering. The President's FY 1996 budget requested an increase of $6 \%$ over FY 1995 for this area, even though the overall NSF budget request increased by only $3 \%$.

The purpose of the Workshop was to obtain input from scientists and engineers conducting research in the AMPP area as well as from potential beneficiaries of that research. The input served to assist NSF in responding to a letter of last Fall from the VA, HUD and Independent Agencies Subcommittee of the U.S. Senate requesting a more detailed plan for each of the seven strategic initiatives. This subcommittee, which oversees NSF funding in the Senate and was previously chaired by Senator Barbara Mikulski (D-Md.), is now chaired by Senator Christopher Bond (RMo.), with Mikulski the ranking minority member. The subcommittee asked NSF, in part, to list key research questions that need to be addressed in order to achieve the national goals of each strategic area, and to indicate a small number of milestones that researchers should target for the next one to five years.

With this challenging task in mind, William Harris, Assistant Director for Mathematical and Physical Sciences, and Joseph Bordogna, Assistant Director for Engineering, as chair and vice-chair respectively of the AMPP strategic area, organized a meeting of 25 panelists on January 12, 1995. Many of the panel were members of the Materials Research Society, including past presidents R.P.H. Chang and Russell Chianelli, and 1989 Von Hippel Award recipient John Goodenough. The Workshop was cochaired by Peter Eisenberger of Princeton University and George Whitesides of Harvard University. It was taken as a given that materials research is strategic since materials play an important and often enabling role in our economy as well as in many advances in our quality of life advances.

The challenge then became one of selecting broad themes and developing milestones which support the major goals of these themes. Three areas-Bio/Biomolecular Materials, Materials for the Information Age, and Special Materials (see article in Washington News)-were selected to be addressed by the panel. These areas of opportunity were chosen to be sufficiently broad to allow flexibility, yet sufficiently well-defined to permit the formulation of meaningful milestones. The objective was not to set priorities, but rather to point out some of the big challenges and state why these are exciting areas. Thus while many possible

A final report of "Advanced Materials and Processing Program (AMPP): Report of NSF Panel on Areas of Opportunity" will be issued by the NSF in the near future. For further information contact Adriaan de Graaf, Division of Materials Research, National Science Foundation, 4201 Wilson Boulevard, Suite 1065, Arlington, VA 22230, fax 703306-0515, e-mail adegraaf@nsf.gov. themes and corresponding milestones could have been reasonably selected, the task was to select just a few and explain why these are important, as is discussed in the full report. Such a task of speaking to a broader audience in terms of overall goals is not one that comes easily to most materials researchers accustomed to delving into the specifics of their work, but it is essential if the field is to receive public recognition of its importance.

The debate on science and technology $R \& D$ funding of research has been rapidly shifting in recent months. Rather than focusing on the balance of the federal investment between strategic and curiosity-driven science, there is now more emphasis on the balance between basic and applied science support. I believe most would agree that basic, strategic, and applied research are not particularly useful distinctions for materials science and engineering, and simply continuing to identify and support the best and most promising research in as efficient a manner as possible is what counts. However, the need to articulate well the benefits of materials research has become more urgent. It is critical in present times of extreme budgetary pressure for the community to do an increasingly better job of representing the purpose and benefits of basic research in general and materials research in particular. Educating society on how science works and the beneficial impact it has on society must be done if this critical element is to receive fair consideration. Materials scientists have to be able to say what is exciting and what the hopes are for the future. I encourage letters to the editor to further raise such issues and debate major themes. Letters can be sent to MRS Bulletin Materials Research Society, 9800 McKnight Road, Pittsburgh, PA $15237-6006$ or emailed to bulletin@mrs.org.

TOM PicRaux Tom Picraux is Chair of the MRS Public Affairs Committee.

1. The seven areas are Advanced Materials and Processing Programs; Biotechnology; Civil Infrastructure Systems; Environment and Global Change Research; High Performance Computing and Communications; Manufacturing; and Science, Math, Engineering and Technology Education.

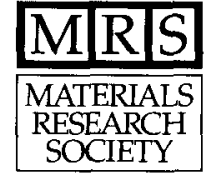

Send Letters to the Editor to: MRS Bulletin, 9800 McKnight Road Pittsburgh, PA 15237-6006 fax: (412) 367-4373, e-mail: Bulletin @mrs.org

Letters must include your full name, institution, address, and phone number. 